\title{
Article
}

\section{Establishing comprehensive oral assessments for children with safeguarding concerns.}

\author{
Park, CM, Welbury, R, Herbison, J and Cairns, A
}

Available at http://clok.uclan.ac.uk/12810/

Park, CM, Welbury, R ORCID: 0000-0002-9322-2440, Herbison, J and Cairns, A (2015) Establishing comprehensive oral assessments for children with safeguarding concerns. British Dental Journal, 219 (5). pp. 231-236. ISSN 0007-0610

It is advisable to refer to the publisher's version if you intend to cite from the work.

http://dx.doi.org/10.1038/sj.bdj.2015.689

For more information about UCLan's research in this area go to http://www.uclan.ac.uk/researchgroups/ and search for <name of research Group>.

For information about Research generally at UCLan please go to http://www.uclan.ac.uk/research/

All outputs in CLoK are protected by Intellectual Property Rights law, including Copyright law. Copyright, IPR and Moral Rights for the works on this site are retained by the individual authors and/or other copyright owners. Terms and conditions for use of this material are defined in the policies page.

\section{CLoK}

Central Lancashire online Knowledge www.clok.uclan.ac.uk






\section{Establishing comprehensive oral assessments for children with safeguarding}

concerns

C. M. Park ${ }^{1}$, R Welbury $^{1}$, J Herbison ${ }^{2}$ and A Cairns ${ }^{1}$

1. Department of Paediatric Dentistry, Glasgow Dental Hospital and School.

\section{University of the West of Scotland}

\section{Abstract}

The dental profession is well placed to contribute important information in child protection cases but no previous research has been reported that assesses the volume or impact of this information. Comprehensive oral assessment clinics were introduced and established as an integral part of comprehensive medical assessments for children with welfare concerns in Greater Glasgow and Clyde. An assessment protocol and standardised paperwork for comprehensive oral assessments were developed to enhance information sharing and patient access to appropriate care. Two cases are presented and discussed to demonstrate the value of dental input.

\section{Keywords}

Multi-disciplinary working, oral assessments, comprehensive medical assessments, dental health, child protection, safeguarding

\section{Introduction}

Previous research has demonstrated that children confirmed as having suffered abuse or neglect have a higher incidence of untreated dental caries and other oral problems ${ }^{1-6}$. Therefore, the dental profession is well placed to contribute important 
information in child protection cases but no previous reports have been published that assess the volume or impact of this information. All previous research has been conducted on children who are confirmed cases of abuse/ neglect. These children are likely to be the "tip of the iceberg" as many children may be too young, scared or ashamed to report what is happening to them ${ }^{7}$. When wellbeing concerns are first highlighted (via health, education, social services or police) dental team members could be invited to share their information regarding oral health and this would add to the body of evidence in these cases. Dentists, dental hygienists and dental therapists are the only health care providers able to diagnose dental and oral disease within their scope of practice. ${ }^{8,9}$ In Greater Glasgow \& Clyde children with an identified wellbeing or safeguarding concern are referred for comprehensive medical assessments (CMAs) as part of the information gathering process. By the late 1990s it was well recognised that CMAs were necessary to identify health needs and coordinate access to health services for vulnerable and at risk children. ${ }^{10}$ The health and welfare needs of children can be overlooked when children are seen by doctors who do not have appropriate training or experience. There is a need to ensure the full involvement of health practitioners, particularly medical staff, in child protection processes. ${ }^{11}$

After many years of work with the NHS policy and planning group the NHS Greater Glasgow \& Clyde (NHS GGC) child protection unit set up CMAs for children with welfare concerns. These clinics started in 2009 and involve obtaining a detailed history and account of circumstances leading to referral plus a full medical 
examination. They are normally requested by social workers but may also be requested by other agencies who contact the child protection advisors.

The most common reason children are referred for a CMA is a concern regarding neglect. The purpose of the CMA is to assess the health of the child and any medical, physical or emotional needs that they may have that are not currently being met by their carer. From December 2009 to March 2012130 children were seen for a CMA with dental input. The dentists staffing these clinics consisted of a team of three community dental officers and the author (CP). In order to ensure all children received the same standard of dental assessment a training package was developed and training organised to standardise recording of clinical dental information.

\section{Role of the dental team in child protection}

Studies of the prevalence of injuries to the head, face and neck of physically abused children have been repeated and it has been consistently shown that $50-75 \%$ of physically abused children have orofacial signs of abuse which should be obvious to a dental practitioner. ${ }^{8,12-15}$ However the literature also suggests that dentists should be involved in the recognition of neglect ${ }^{16-18}$ and sexual abuse ${ }^{19,20}$. Neglect should be considered if parents have access to, but persistently fail to obtain treatment for their child's tooth decay. ${ }^{21}$

The Scottish Government's National Guidance specifically covers the roles and responsibilities of dental care practitioners. In keeping with the General Dental Council's policy ${ }^{22}$ the Scottish Government Guidance agrees that the dental team should have the knowledge and skills to be able to identify concerns about a child's 
welfare and know how and with whom to share that information. The National Guidance also recognises that dental care practitioners often come into contact with vulnerable children and are in a position to identify possible child abuse or neglect from their examination of oral injuries or oral cleanliness (hygiene). ${ }^{23}$

\section{The Role of the Dentist at CMAs}

The first pilot CMA clinics in Glasgow had no dental input. The only oral assessment was a comment from a paediatrician on the teeth and a grading of any tooth decay as mild, moderate or severe. There are no texts which grade dental caries in this way and this terminology would not be recognisable to any dental practitioner. Although the attempts that were made were admirable it demonstrated a lack of knowledge in this specialised field and a failure to include the dental profession. As previously noted; the health and welfare needs of children can be overlooked when children are seen by doctors who do not have appropriate training or experience. ${ }^{11}$ The same could also be said of children's oral health needs. The child protection unit subsequently agreed that in CMA's the oral examination should be performed by someone highly skilled in the assessment of the oral cavity, namely a dentist.

The aim of this report is to describe the establishment of regular input from paediatric dentistry to the CMAs, to increase interdisciplinary collaborative working, thereby underpinning the importance of interdisciplinary communication.

In turn we hoped that this would help dental services respond to the needs of these vulnerable children and lead to the development of care pathways for management of dental neglect. These plans were designed to meet with the recommendations set 
out in the British Society of Paediatric Dentistry's policy document on Dental Neglect. ${ }^{17}$

The benefit for the children seen at these clinics would be a holistic approach to the identification of medical and dental needs. This health information would be easily collated and interpreted to provide a comprehensive report for Child Protection Case Conferences. It would also ensure appropriate professionals attended case conferences when required and thus allow the immediate referral of these children into the services they require.

Ethical approval was gained from the West of Scotland Research Ethics Committee. At the clinics the parent or carer with parental responsibility for the child, and the social worker who made the referral attended with the child. This allowed the social worker who made the referral to get immediate verbal feedback. As well as a full verbal opinion provided to the parent/ carer and social worker, a standard pro forma clinical data collection sheet and a report of the examination were also completed. A clinical pro forma or check list has been reported to be beneficial in allowing clinicians to concentrate on complex issues while the simple ones are addressed for every patient, every time. ${ }^{24}$

\section{Development of assessment paperwork and protocol}

The paperwork was based on a previously established CMA form. From this document a four page comprehensive oral assessment (COA) form was developed and piloted. Input from medical colleagues involved in the pilot allowed the form to be simplified to its current format which is seen in figure 1. 
The clinical examination consisted of a visual inspection for all children in accord with the British Association for the Study of Community Dentistry's criteria ${ }^{25}$ and a basic periodontal examination for all of the children aged 7 years and older. ${ }^{26}$ The examining dentist then provided a written summary of their findings and a plan for any action required.

\section{Development of "Dental appendix to Comprehensive medical assessment report"}

Following the clinical examination a dental appendix report (figure 2) was completed and added to the paediatrician's medical report. This was requested by the paediatricians who wished the results of the dental examination to be reported by a dentist rather than to summarise the findings themselves. The appendix also included details of simple dental targets that were agreed with the accompanying adult as well as the clinic location for future dental appointments (treatment of active caries and a comprehensive preventive treatment plan). Setting targets for improvement is an action derived from multiagency good practice and it has been suggested that this might usefully be undertaken more often by paediatric dentists. ${ }^{27}$

\section{Management support}

There have been challenges to overcome in the development of COA's for children with a welfare concern. Support from management in the Oral Health Directorate of NHS GGC was essential to start the clinics and to maintain them. This was achieved by regular meetings and update emails to management. Understandably management wanted to quantify the clinical involvement that would be required for 
the clinics from the start, but this has been difficult as the project was in its infancy and is still consistently gathering momentum.

\section{Development of roles and responsibilities of dental co-ordinator}

One of the most challenging aspects of these clinics is ensuring there is a dentist available to attend the CMA's. This led to the development of a "roles and responsibilities" document for the co-ordinator of the dental input.

The document was developed with guidance from "Protecting Children and Young People: Framework for Standards ${ }^{28}$ which states that professionals who work directly with children should understand child development and be skilled and experienced in communicating with children. They should understand the impact of parents' behaviour on the well-being of their children and know what action to take to protect the interests of each child, and make sure it is taken. They should also be knowledgeable and skilled in making informed assessments, plans and decisions; able to account for their assessments and decisions and competently present these in court, at hearings or in meetings; skilled in interagency working; and understand the role and contribution of other professionals ${ }^{28}$. These skills and attributes are part of the skill set that is acquired through a recognised specialist training pathway in paediatric dentistry, therefore it is sensible that the dental co-ordinator for these clinics should be someone on the General Dental Council's Specialist List in Paediatric Dentistry.

In addition these professionals should be equipped to deal with difficult situations including conflict and be supported by their colleagues and agencies and have 
systems in place to monitor this. They should also know the limits of their own knowledge and expertise and call on the skills of others or specialist services when needed. Importantly these professionals need to keep up to date with relevant legislation, research, good practice and guidance and their agencies should support them to do so ${ }^{28}$. There is also the possibility that any of the dental professionals involved in the CMAs may be asked to give evidence in court so it is important that the dental co-ordinator has training in court skills and can support and advise the other dental team members involved in identifying their training needs.

\section{Case reports}

To illustrate the importance of the COA'S as part of a CMA and to demonstrate the important role that dentistry plays in child protection, selected cases have been included.

\section{Case 1}

Table 1 Case 1: A 13 year old

Concerns raised prior to CMA

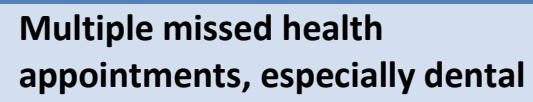

Poor home conditions
Issues identified during preparatory investigation and dental exam at CMA

Significant previous dental treatment including exposure and bonding under general anaesthesia

Multiple missed appointments at Dental Hospital in paediatrics and orthodontics in 2 blocks.

After the first block of missed appointments "social issues" were noted as the reason for missed appointments

Gold chain visible in mouth, with unerupted tooth still unerupted and loss of space for unerupted tooth 
Case 1 is shown in table 1 . The social worker involved with this family contacted the Child Protection Unit requesting a CMA for this child and their siblings. The social worker advised the Child Protection Unit that there was an accumulation of various concerns for the family which included missed health appointments for the children, particularly dental appointments. Apart from the dental concerns no other health issues were identified. Following the CMA a remedial dental treatment plan was developed and implemented following direct referral to the Dental Hospital with very close support for the child from social services. Without the dental input in the CMA, many of the child's wellbeing needs may have been overlooked, and certainly the treatment she required would not have been as efficiently organised. This case highlighted numerous learning points for those working in both primary dental care and secondary (hospital) dental care including:

- Long standing problems with missed health appointments (most notably dental in this case) can be the main wellbeing concern for vulnerable children.

- After the block of missed appointments following 'social issues' were noted, however after this the child then failed to attend again and only a standard letter was sent out to the family telling them they had been discharged according to hospital policy. The BSPD policy document ${ }^{17}$ recommends that 
missed appointment policies should not be punitive. This was an opportunity missed to help this family and safeguard this child's wellbeing.

- The child's siblings had also missed appointments for both assessment at the dental hospital and later for dental extractions under general anaesthesia. In a large dental hospital there is often no way of knowing the attendance history of a child's siblings and this is different from a general dental practice where the practice dental team may know the family more closely. In this case it should have raised alarm bells with the child's previous GDP when they received letters saying the children had failed to attend their appointments. These specific issues are mentioned in the "Child Protection and the Dental Team" document ${ }^{16}$ that was sent to all dental practices in 2006 and is also available online (www.cpdt.org.uk). It may be that the original GDP for this child was one of nearly half of GDPs in Scotland who have not read this document. ${ }^{29}$

\section{Case 2}

Table 2 Case 2: Siblings in one family

Issues identified during preparatory investigation and dental exam at CMA

Parent focussed solely on baby (who has freshly laundered clothes, clean skin and hair and good oral hygiene), not interested in older children

Ingrained dirt on school uniforms

Skin and hair visibly dirty

Older children smelt unclean

Older children have active gross dental caries and poor oral hygiene

Parent blames children for oral condition "they never brush when I tell them to" 
Case 2 is shown in table 2. This family consisted of three children aged 8 years, 6 years and 6 months respectively. Both older children were very compliant for dental examination. The children were registered with a general dental practitioner.

The children's parent was made aware of the dental needs of the children and targets were set. The parent elected to take the children back to their own dentist for treatment. A copy of the dental appendix to was sent to the children's general dental practitioner and a telephone call with the dentist confirmed they were registered but had failed to complete treatment. A few weeks later the dentist contacted the examining COA dentist as the children had not returned for their dental treatment. The COA dentist contacted the children's social worker who was able to inform them that the older children had been removed from the home and accommodated by social services. The CMA had played a role in the decision to remove the children from their parents. Without the dental input the children's wellbeing needs would not have been fully assessed. In addition the social worker asked permission to pass the dental report onto the new family GDP that the children would be attending.

Once again learning points were raised and included:

- The older siblings in the family were obviously dirty and smelly on extra-oral examination and intra-oral examination revealed gross caries. The children were registered with a GDP, but the family were irregular attendees. The children were very compliant during the examination and the GDP agreed 
that they had also been compliant with previous treatment. Despite this, and coupled with their appearance, no concerns had been raised by the GDP. Again these alerting issues are mentioned in "Child Protection and the Dental Team". ${ }^{16}$

- The use of target setting in this case was helpful in that it made clear to the family what was expected. As the targets had been set both the family and GDP knew what was expected so the GDP had a lower tolerance for future missed dental appointments.

- This case highlighted the importance of information sharing. Without informing the GDP that their patients had been subject to a CMA and required dental treatment, the GDP would not have been aware of the increased importance of adequate follow up for these children. Additionally if the GDP hadn't contacted the examining COA dentist to share the information of the subsequent failure to attend it may never have been discovered that the children had been accommodated.

\section{Discussion}

Setting up clinics to include a COA as part of a CMA has never been reported in the literature. The idea for CMA's has been around since the late 1990's and it is recognised that medical staff should have more of a role in informing those who make the decisions on the welfare of children. The model we have produced can be replicated elsewhere and it adds to the information available to those making the 
very difficult decisions with regard to what is best for children with identified wellbeing concerns.

\section{Conclusion}

Comprehensive oral assessment clinics have been successfully introduced and established as an integral part of CMAs for children with a welfare concern in Greater Glasgow and Clyde. An assessment protocol and standardised paperwork for COA's has been developed to enhance information sharing and patient access to appropriate care. This included a "dental appendix" to the established CMA report. Discussion of cases from the COAs demonstrates the usefulness of dental input in these cases.

\section{Acknowledgements}

Grateful thanks is given to all involved with the CMAs including all the staff of the NHS GGC child protection unit, all the community paediatricians involved with the CMAs, the admin staff at each CMA site, the NHS GGC clinical effectiveness department and all the dentists involved. We would especially like to acknowledge and thank Marie Valente, Head of the NHS GGC Child Protection Unit who along with the Clinical Director of the Child Protection Unit $(\mathrm{JH})$ was instrumental in the set-up of the CMAs. 


\section{References}

1. Greene PE, Chisick MC, Aaron GR. A comparison of oral health status and need for dental care between abused/neglected children and nonabused/non-neglected children. Pediatr Dent 1994;16: 41-45

2. Olivan G. Untreated dental caries is common among 6 to 12 -year-old physically abused/neglected children in Spain. Eur J Public Health 2003; 13: 91-92.

3. Mezzich AC, Bretz WA, Day B-S, Corby PM, Kirisci L, Swaney M, Cornelius JR, Weyant RJ. Child neglect and oral health problems in offspring of substanceabusing fathers. Am J Addict 2007; 16: 397-402.

4. Valencia-Rojas N, Lawrence HP, Goodman D. Prevalence of early childhood caries in a population of children with history of maltreatment. J Public Health Dent 2008; 68: 94-101.

5. Montecchi PP, Di Trani M, Sarzi Amade D, Bufacchi C, Montecchi F, Polimeni $A$. The dentist's role in recognizing childhood abuses: study on the dental health of children victims of abuse and witnesses to violence. Eur J Paediatr Dent 2009; 10: 185-187

6. Keene E J, Skelton R, Day P F, Munyombwe T, Balmer R C. The dental health of children subject to a child protection plan. Int J Paediatr Dent. Article first published online Dec 15 2014. DOI: 10.1111/ipd.12149

7. NSPCC. Statistics on child abuse. Online information available at: http://www.nspcc.org.uk/preventing-abuse/research-andresources/statistics/ (accessed June 2015).

8. Cairns AM, Mok JYQ, Welbury RR. Injuries to the head, face, mouth and neck in physically abused children in a community setting. Int J Paediatr Dent 2005; 15: 310-318

9. General Dental Council. Scope of Practice. 2013. Online information available at: https://www.gdcuk.org/Newsandpublications/Publications/Publications/Scope\%20of\%20Prac tice\%20September\%202013.pdf (accessed June 2015).

10. Scottish Office.1998. Protecting Children - A Shared Responsibility. Online information available at: 
http://www.scotland.gov.uk/Resource/Doc/47034/0023910.pdf (accessed July 2013).

11. HM Inspectorate of Education. 2009. Joint inspection of services to protect children and young people in the Glasgow City Council area. Available at: http://www.educationscotland.gov.uk/Images/GlasgowCityCouncillns20090 324 tcm4-699798.pdf. (accessed July 2013).

12. Becker DB, Needleman HL, Kotelchuck M. Child abuse and dentistry: orofacial trauma and its recognition by dentists. J Am Dent Assoc 1978; 97: 24-28.

13. Malecz RE. Child abuse, its relationship to pedodontics: a survey. ASDC J Dent Child 1979; 46: 193-194.

14. da Fonseca MA, Feigal RJ, ten Bensel RW. Dental aspects of 1248 cases of child maltreatment on file at a major county hospital. Pediatr Dent 1992; 14: 152-157

15. Jessee SA. Physical manifestations of child abuse to the head, face and mouth: a hospital survey. ASDC J Dent Child 1995; 62: 245-249.

16. Harris J, Sidebotham P, Welbury R et al. 2013. Child Protection and the Dental Team. An introduction to safeguarding children in dental practice. Sheffield: Committee of Postgraduate Dental Deans and Directors. Online information available at: http://www.cpdt.org.uk (accessed January 2015)

17. Harris JC, Balmer RC, Sidebotham PD. 2009. British Society of Paediatric Dentistry: a policy document on dental neglect in children. Int J Paediatr Dent; Available at: http://www.bspd.co.uk/LinkClick.aspx?fileticket=P2H2L6M4ISO\%3d\&tabid=6 $\underline{2}$ (accessed July 2013) DOI: 10.1111/j.1365-263X.2009.00996.x

18. Balmer R, Gibson E, Harris J. Understanding child neglect. Current perspectives in dentistry. Prim Dent Care 2010; 17: 105-109.

19. ten Bensel RW, King KJ. Neglect and abuse of children: historical aspects, identification, and management. ASDC J Dent Child 1975; 42: 348-358.

20. Fontana VJ. A physician's view of responsibility in reporting child abuse. Spec Care Dentist 1986; 6: 55-57

21. National Collaborating Centre for Women's and Children's Health. When to suspect child maltreatment: full guidance. Clinical Guideline 89. National Institute for Health and Clinical Excellence. Royal College of Obstetricians and Gynaecologists: London, 2009. 
22. General Dental Council. Guidance on child protection and vulnerable adults. 2013.Online information available at: http://www.gdcuk.org/Dentalprofessionals/Standards/Documents/Guidance\%20on\%20Child \%20Protection\%20and\%20Vulnerable\%20Adults\%20November\%202013.pdf (accessed June 2015).

23. Scottish Government. 2014. National Guidance for Child Protection in Scotland 2014. Online information available at: http://www.gov.scot/Resource/0045/00450733.pdf (accessed June 2015).

24. Weiser TG, Haynes AB, Lashoher A, Dziekan G, Boorman DJ, Berry WR, Gawande AA. Perspectives in quality: designing the WHO Surgical Safety Checklist. Int J Qual Health Care 2010; 22: 365-370.

25. Pitts NB, Evans DJ, Pine CM. British Association for the Study of Community Dentistry (BASCD) diagnostic criteria for caries prevalence surveys-1996/97. Community Dent Health 1997; 14 Suppl 1: 6-9.

26. Clerehugh V, Kindelan S. Guidelines for periodontal screening and management of children and adolescents under 18 years of age. British Society of Periodontology and The British Society of Paediatric Dentistry. 2012. Online information available at http://www.bsperio.org.uk/publications/downloads/54 090016 bsp bspdperio-guidelines-for-the-under-18s-2012.pdf (accessed July 2013).

27. Harris JC, Elcock C, Sidebotham PD, Welbury RR. Safeguarding children in dentistry: 2. Do paediatric dentists neglect child dental neglect? Br Dent J 2009; 206 (9): 465- 470.

28. Scottish Executive. Protecting Children and Young People: Framework for Standards. The Stationery Office: Edinburgh, 2004. Available at: http://www.scotland.gov.uk/Publications/2004/03/19102/34603 (accessed July 2013).

29. Harris C.M, Welbury R, Cairns A.M. The Scottish dental practitioner's role in managing child abuse and neglect. British Dental Journal 2013; 214 (9): E24 DOI:10.1038/sj.bdj.2013.435 